\title{
Recorrido geológico y mineralógico por la comarca del Maestrazgo: Desde Cantavieja a Villarroya de los Pinares y Allepúz
}

\author{
Josep Maria Mata-Perelló \\ Joaquim Sanz Balagué \\ Jaume Vilaltella
}

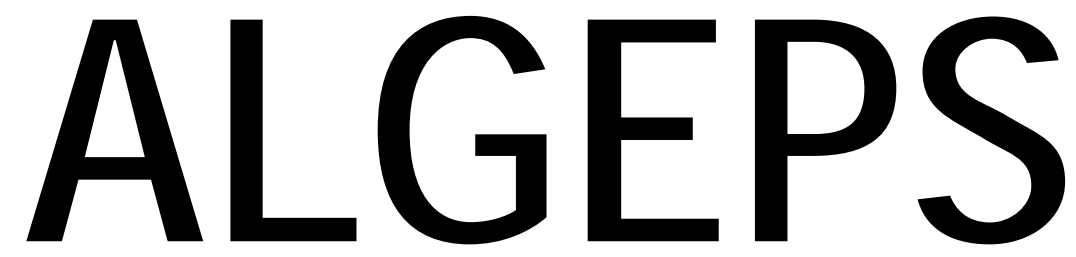

\section{REVISTA DE GEOLOGIA}

\section{n. 4}

OCTUBRE 2015 


\title{
RECORRIDO GEOLÓGICO Y MINERALÓGICO POR LA COMARCA DEL MAESTRAZGO: DESDE CANTAVIEJA A VILLARROYA DE LOS PINARES I ALLEPÚZ
}

\section{Josep Maria Mata-Perelló}

Museu de geologia Valentí Masachs, Escola Politècnica Superior d'Enginyeria de Manresa (EPSEM), Universitat Politècnica de Catalunya · BarcelonaTech (UPC), 08272 Manresa, Spain

\section{Joaquim Sanz Balagué}

Departament d'Enginyeria Minera i Recursos Naturals (EMRN), Escola Politècnica Superior d'Enginyeria de Manresa (EPSEM), Universitat Politècnica de Catalunya - BarcelonaTech (UPC), 08272 Manresa, Spain

\section{Jaume Vilaltella}

Paraules clau: Patrimoni geològic i miner; Sistema ibèric; Maestrazgo

\begin{abstract}
Resumen
Itinerario realitzado el día 7 de diciembre de 2014. En este caso, el presente itinerario se desarrollará totalmente por la denominada Rama Aragonesa de la Cordillera Ibérica. En este recorrido se irán encontrando afloramientos de los materiales mesozoicos (del Triásico, del Jurásico y del Cretácico, especialmente de este último). En concreto, el recorrido se realizará en buena parte por la denominada Cuenca del Maestrazgo. Los materiales antes mencionados se hallan levemente influenciados por las características la denominada Zona de Enlace de la Cordillera Ibérica con el Sistema Mediterráneo; aunque en todos los casos van a predominar las estructuras ibéricas (WNW-ESE) sobre las "catalanas" (NNE-SSW), al hallarnos plenamente dentro del dominio ibérico.
\end{abstract}

Por otra parte, este itinerario discurrirá por una de las comarcas de Teruel, concretamente por la del Maestrazgo (con centro en Cantavieja). Esta comarca forma parte del Maestrazgo histórico. 


\section{ADVERTENCIAS PREVIAS}

Al igual que en otras ocasiones, en los recorridos de RECERCA GEOLÒGICA I NATURALİSTICA..., si se dispone del tiempo suficiente, podrán realizarse todas las paradas e hijuelas propuestas. En caso contrario, recomendamos prescindir de las calificadas con el nombre de PARADAS - CONDICIONALES.

Así se presentará un recorrido aproximado, por diferentes lugares de las comarcas del Maestrazgo y de las Cuencas Mineras, con una serie de PARADAS situadas entre las poblaciones de Cantavieja (la capital de la primera comarca) y Allepúz (ya dentro de la segunda).

Aun así, el recorrido podría variarse en función del estado de conservación de los caminos, de la situación meteorológica, o por hallar sobre la marcha lugares más interesantes, para poder efectuar las pertinentes observaciones.

Posiblemente, en algunos tramos del recorrido se pasará por caminos en mal estado de conservación, circunstancia por la cual será mejor hacerlos a pie. Este es el caso del camino de aproximación a alguna de zonas de patrimonio minero.

En cualquier caso, y como es natural, es necesario tener un absoluto cuidado y respeto hacía el Medio Natural, a lo largo de todo el recorrido.

\section{BREVE INTRODUCCIÓN}

En este caso, el presente itinerario se desarrollará totalmente por la denominada Rama Aragonesa de la Cordillera Ibérica. En este recorrido se irán encontrando afloramientos de los materiales mesozoicos (del Triásico, del Jurásico y del Cretácico, especialmente de este último). En concreto, el recorrido se realizará en buena parte por la denominada Cuenca del Maestrazgo. Los materiales antes mencionados se hallan levemente influenciados por las características la denominada Zona de Enlace de la Cordillera Ibérica con el Sistema Mediterráneo; aunque en todos los casos van a predominar las estructuras ibéricas (WNWESE) sobre las "catalanas" (NNE-SSW), al hallarnos plenamente dentro del dominio ibérico.

Por otra parte, este itinerario discurrirá por una de las comarcas de Teruel, concretamente por la del Maestrazgo (con centro en Cantavieja). Esta comarca forma parte del Maestrazgo histórico.

\section{OBJETIVOS FUNDAMENTALES DE ESTE ITINERARIO}

Los objetivos fundamentales que se pretenden conseguir con la realización de este itinerario, se pueden concretar en los siguientes aspectos generales: 
1.- Observación de los materiales mesozoicos (que según los lugares se reparten entre el Triásico, el Jurásico y el Cretácico, con un claro predominio de este último) que encontraremos por diferentes lugares del recorrido. Estos materiales forman parte del Sistema Ibérico en la Cuenca del Maestrazgo; en los sectores septentrionales de la Sierra de Gúdar.

2.- Observación de la estructura, en este recorrido, del borde oriental de la denominada Cuenca del Maestrazgo. Estas estructuras se hallan también influenciadas por la Zona de Enlace de la Cordillera Ibérica con el Sistema Mediterráneo.

3.- Observación de las diferentes mineralizaciones que iremos encontrando a lo largo del recorrido, como las mineralizaciones ferruginosas asociadas a lignitos, entre los materiales cretácicos de la Formación Escucha, en Allepúz.

4.- Observación de las explotaciones mineras desarrolladas sobre las mineralizaciones anteriores, y también sobre otras, a lo largo del recorrido del itinerario.

5.- Observación de los impactos producidos sobre el Medio Natural, como consecuencia de las explotaciones anteriores.

6.- Observación (si se da el caso) de las restauraciones llevadas a cabo, con la finalidad de mitigar los impactos anteriores.

7.- Observación, a lo largo de todo el recorrido, de los distintos PIG (Puntos de Interés Geológico) i de los distintos PIM (Puntos de Interés minero), integrantes de nuestro Patrimonio Geológico y Minero.

\section{ANTECEDENTES}

No tenemos conocimiento de ningún itinerario geológico y minero que discurra por estos sectores. De forma marginal podemos mencionar dos trabajos: MATA-PERELLÓ (2003) y MATA-PERELLÓ y MONTANÉ GARCÍA (2004). Otros antecedentes son: MATA-PERELLÓ, POCOVÍ JUAN y VILALTELLA FARRÀS (2006a y 2006b)

Sin embargo, tenemos antecedentes nuestros, en relación a las mineralizaciones presentes en esta zona, tanto a las situadas en esta comarca como en las vecinas (a las del Maestrazgo y Cuencas Mineras). Se trata de MATA-PERELLÓ (1991a, 1991b y 1991c)

En relación con las características geológicas citaremos el trabajo de PEÑA et altri (1984). Asimismo, en relación al patrimonio geológico citaremos el trabajo publicado por la GADMA (2001).

Todos estos trabajos se hallaran debidamente relacionados en el apartado de REFERENCIAS BIBLIOGRÁFICAS, que figura al final del presente trabajo.

\section{RECORRIDO DEL ITINERARIO}

El recorrido de este itinerario, se iniciará en la población de Cantavieja (la capital de la comarca del Maestrazgo). Desde ahí se saldrá hacía el NW, por la carretera que conduce a Teruel, la A - 226, yendo primero al Puerto del Cuarto Pelado, en donde se realizará la primera parada, iniciándose ahí el recorrido real. 
Desde ahí, se irá posteriormente hacía Fortanete, hacia el Puerto de Villarroya y hacia la población de Villarroya de los Pinares. En este tramo se realizaran diversas paradas.

Luego, al llegar a esta última población, el recorrido se encaminará hacía Allepúz. En este tramos se efectuaran también diversas paradas, terminando el recorrido al sobrepasar la última población citada.

\section{DESCRIPCIÓN DEL ITINERARIO}

Como de costumbre, estructuraremos el recorrido del itinerario en una serie de PARADAS, que a continuación iremos viendo. En cada una de estas paradas haremos un breve comentario (geológico o mineralógico, según acontezca). Por otra parte, en cada caso indicaremos (entre paréntesis) la hoja topográfica en donde se halla la parada.

Para ello, utilizaremos las hojas del Instituto Geográfico y Catastral de España, publicadas a la escala de 1:50.000. En este caso, las hojas serán las siguientes: 543 (o de Villarluengo), 544 (o de Forcall) y 568 (o de Alcalá de la Selva).

Así pues, la relación de las paradas que componen el recorrido de este itinerario, son las siguientes:

\subsection{PARADA 1. EL PUERTO DEL CUARTO PELADO, (término municipal de Cantavieja, comarca del Maestrazgo). (Hoja 544).}

El recorrido lo iniciaremos en la localidad turolense de Cantavieja (la capital comarcal del Maestrazgo). Desde ahí, tomaremos la carretera autonómica aragonesa A - 226, con la finalidad de desplazarnos hacía el Puerto del Cuarto Pelado (yendo en el sentido hacía Teruel). En este lugar haremos la primera parada, a $10 \mathrm{Km}$ del pueblo.

En este recorrido, habremos ido encontrando los materiales mesozoicos, que en todas las ocasiones pertenecen al Cretácico. Así, inicialmente habremos encontrado las calizas del Cretácico Inferior, sobre las que se asienta la población de Cantavieja. Después habremos ido subiendo (estratigráficamente). Más adelante, al llegar al lugar de la parada, nos habremos encontrado frente a unos afloramientos del Albiense, de los materiales de la Formación Escucha y de la Formación Utrillas. En cualquier caso, estos materiales forman parte de la Cuenca del Maestrazgo, del Sistema Ibérico.

En este lugar hay unas interesantes formas de solifluxión, por deslizamiento sobre la base de materiales arcillosos. Estos movimientos, tienen su origen en posibles causas periglaciares. Así, en este lugar, en la vertiente septentrional de la Sierra del Cuarto Pelado, nos encontramos en la parte superior de las calizas del Cenomaniense; mientras que en la base hay los materiales blandeo del Albiense. En estas condiciones, y en un clima periglacial, se han originado unas interesantes solifluxiones". FOTOGRAFIA 1. 


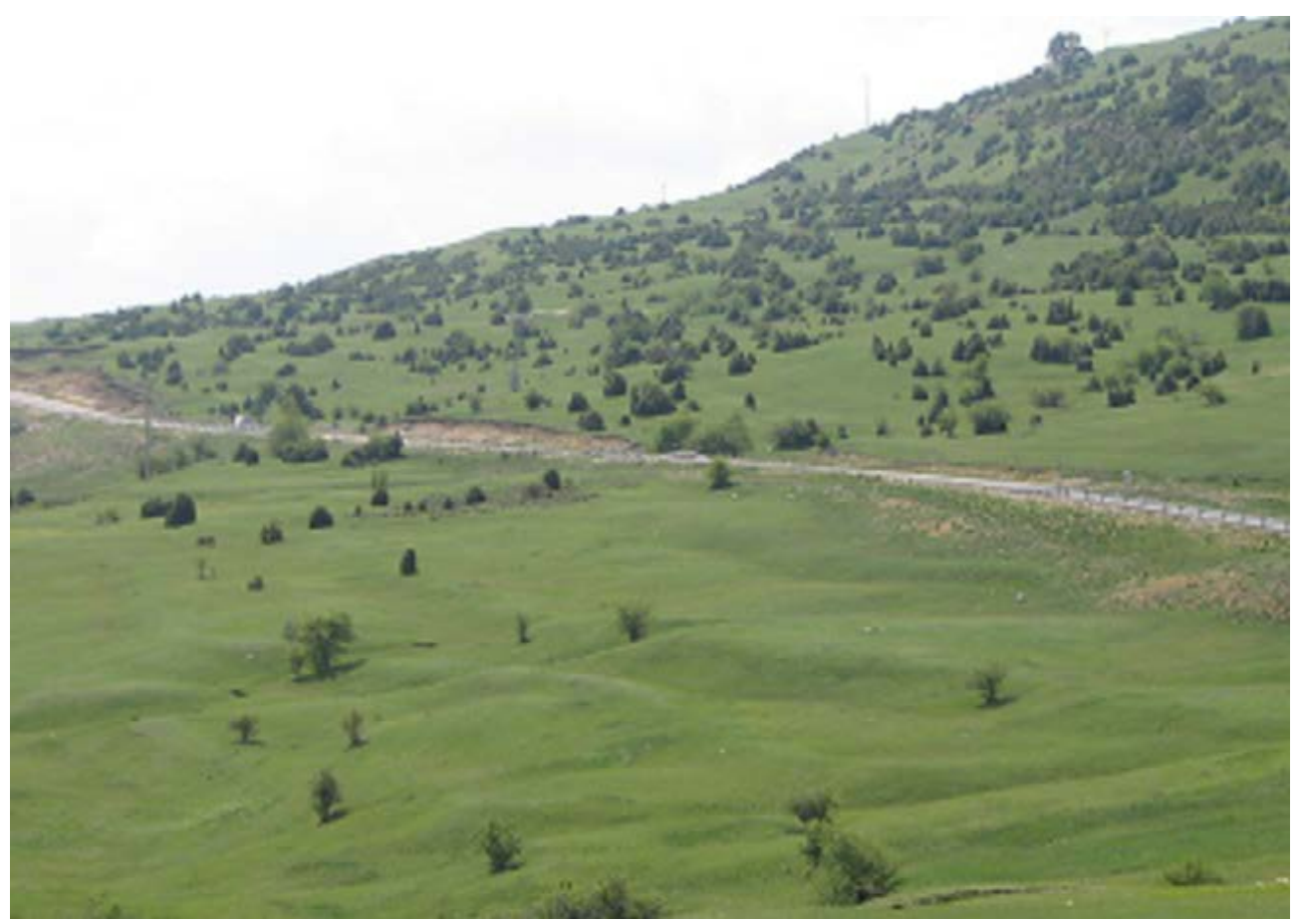

FOTOGRAFIA 1. PARADA 1

Un aspecto de los movimientos en masa, del Puerto del Cuarto Pelado. Cantavieja

Estos fenómenos son consecuencia de que el agua de escorrentía, se ha filtrado entre los materiales antes citados. Esto confiere una cierta plasticidad (en función de las características de estos materiales), circunstancia por la cual se ha producido la fractura de les diferentes niveles, produciéndose unos movimientos gravitacionales.

Cabe indicar, en relación con esta solifluxión, con estos movimientos lobulares en masa, que al construirse la carretera nueva no se tuvo en cuenta. Una de las consecuencias de esta omisión, son los continuos deslizamientos que se producen sobre la mencionada carretera. Algunos de ellos son muy cercanos al cruce de carreteras en donde hacemos la presente parada. FOTOGRAFIA 2. 


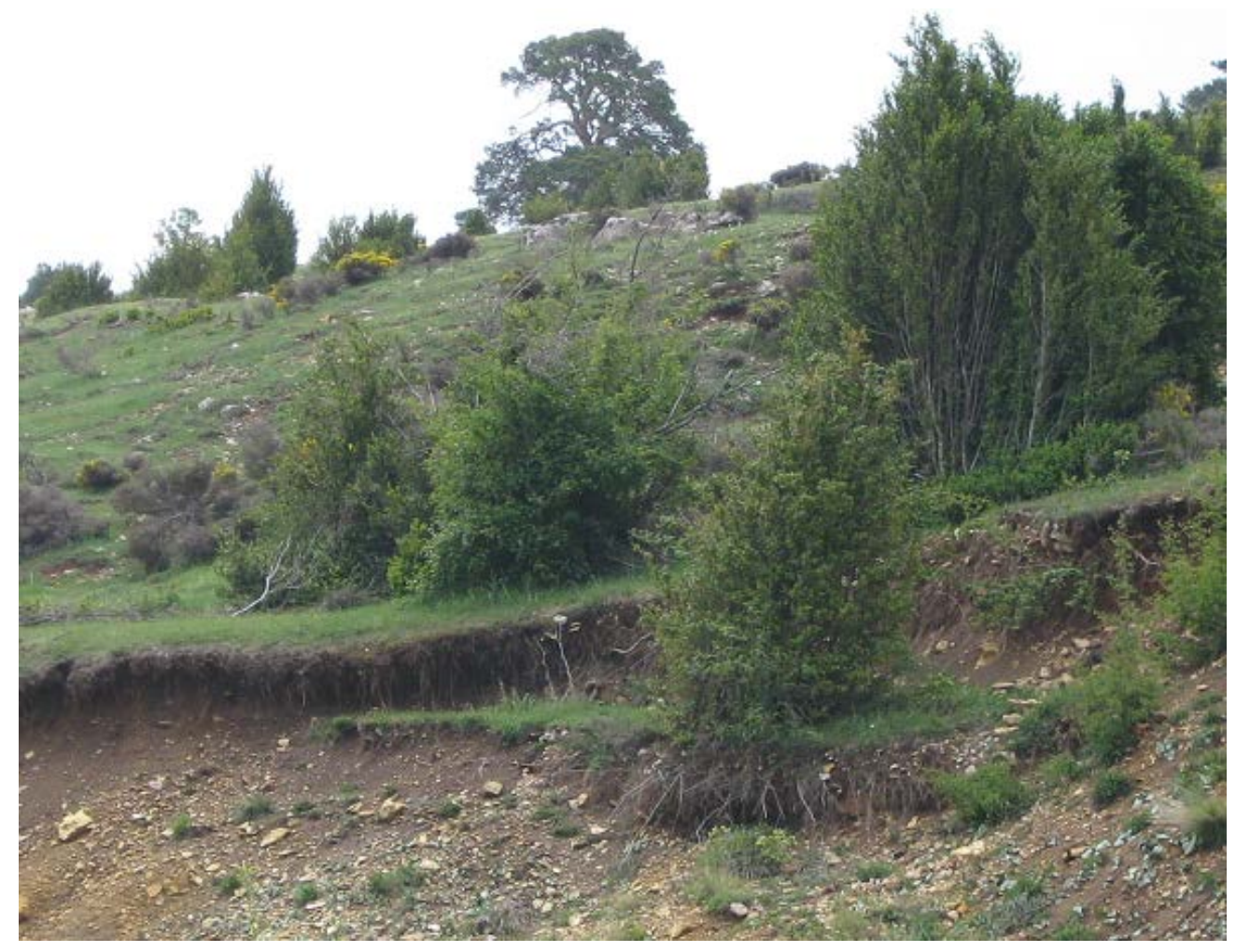

FOTOGRAFIA 2. PARADA 1.

Uno de los numerosos derrumbamientos sobre la carretera A - 226. Cantavieja

\subsection{PARADA 2 - CONDICIONAL. PUENTE SOBRE EL RÍO PITARQUE, (término municipal de Fortanete, comarca del Maestrazgo). (Hoja 543).}

Tras realizar la parada anterior, cabe continuar por la carretera autonómica aragonesa A - 226, yendo ahora hacía el poniente. Así, en unos $10 \mathrm{Km}$ se llegará al pueblo de Fortanete. A la salida del mismo, se realizará una nueva parada.

En este recorrido, tras sobrepasar los afloramientos de los materiales del Albiense, hemos encontrado materiales carbonatados que pertenecen al Cenomaniense. Luego, bajando hacia Fortanete, hemos visto afloramientos de materiales carbonatados del Cretácico Superior, del Turoniense, fundamentalmente. Estos son los materiales que aparecen cerca de la población. Por otra parte, cabe decir que nos hemos estado desplazando dentro de la Rama Castellana del Sistema Ibérico, en donde nos encontramos ahora situados.

En este lugar, nos hallamos sobre el cauce del rio Pitarque. Cabe decir que este rio no nace en el Nacimiento del rio Pitarque", situado al Norte de donde ahora estamos, sino que nace cerca de donde estamos, por la conjunción de la Rambla de Mal Burgo y el Barranco del Herrero, a escasa distancia del puente en donde estamos.

\subsection{PARADA 3. EL PUERTO DE VILLARROYA, (términos municipales de Villarroya de los Pinares, y de Fortanete, comarca del Maestrazgo). (Hoja 543).}


Tras realizar la parada anterior, cabe continuar por la carretera, continuando hacía el poniente. Así, en unos $10 \mathrm{Km}$ se llegará al Puerto de Villarroya, en donde haremos la presente parada, dentro de este recorrido, justo en el límite de los términos municipales de los dos municipios.

En este recorrido habremos ido encontrando los materiales citados en los tramos anteriores, ya que nos habremos estado moviendo en todo momento por la denominada Cuenca del Maestrazgo; es decir, seguimos en el Sistema Ibérico (dentro de su Rama Aragonesa). Así, en este lugar se ven afloramientos de los materiales carbonatados del Cretácico Superior, fundamentalmente pertenecientes al Turoniense. FOTOGRAFIA 3.

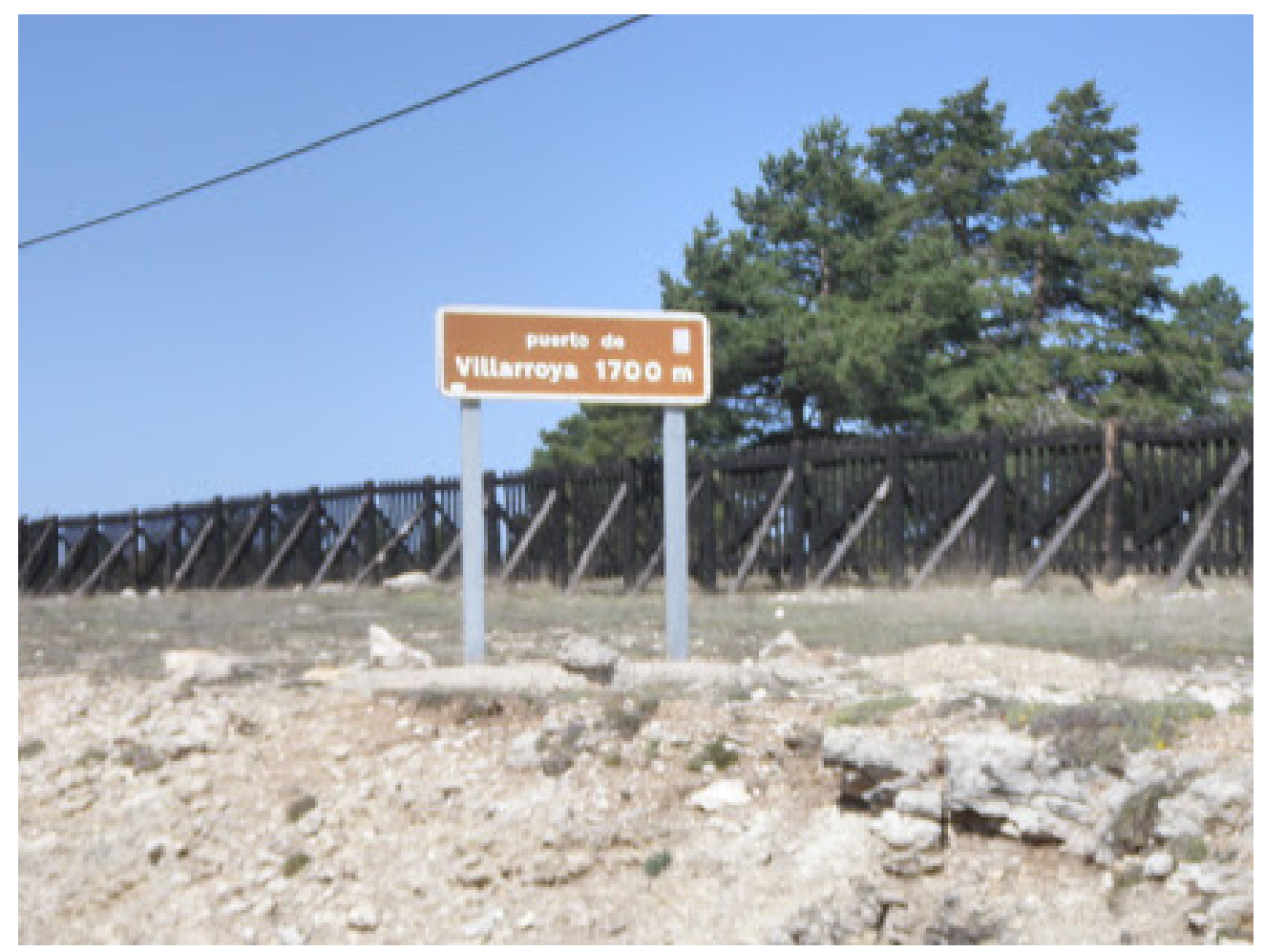

FOTOGRAFIA 3. PARADA 3

Un aspecto del afloramiento de las calizas del Cretácico Superior en el Puerto de Villarroya.

Fotografia extraída de INTERNET: http://1001puertosdemontana.blogspot.com.es/2011/04/puerto-de-villarroya.html

Desde este lugar, mirando hacia el Norte, puede observarse todo el conjunto de los sectores septentrionales de la Cuenca del Maestrazgo. Asimismo, es posible ver algunas de las explotaciones mineras de la comarca minera, de las Cuencas Mineras, en donde acabamos ahora de entrar. Así, puede verse perfectamente la denominada Penillanura Fundamental. FOTOGRAFIA 4. 


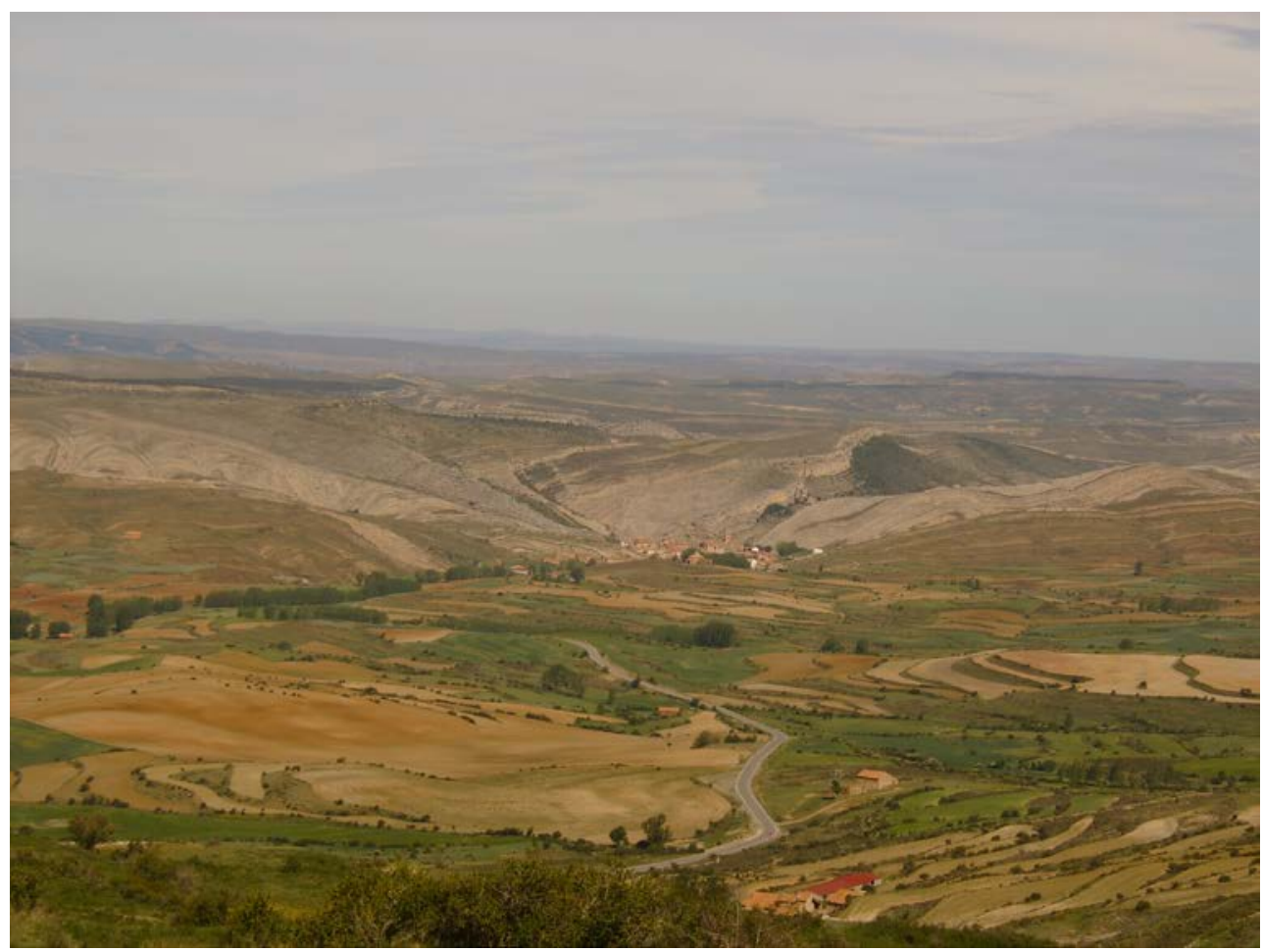

FOTOGRAFIA 4. PARADA 3

Cuenca del Guadalupe en Villarroya de los Pinares.

A la izquierda de la fotografía puede entreverse la denominada Penillanura Fundamental

También puede observarse la cuenca del río Guadalupe, que nace en las inmediaciones de donde estamos ahora, pasando por Villaroya de los Pinares y dirigiéndose luego a Aliaga.

Por otra parte, muy cerca de donde estamos ahora (apenas a 1'5 Km) hay una mineralización ferruginosa, en el Barranco Tinaja (PARADA 5-BIS, hoja 568). En este lugar hay un afloramiento de lignitos cretácicos del Albiense, pertenecientes a la Formación Escucha. Por alteración de la PIRITA incluida en los lignitos, se han formado minerales como: GOETHITA (limonítica y terrosa), MELANTERITA y YESO. Este último al atacar el Ácido Sulfúrico formado en la alteración, a la CALCITA, presente en estos niveles. No obstante, por lo que concierne a los lignitos, cabe decir que tienen muy poca importancia.

\subsection{PARADA 4. ESTRECHOS DEL GUADALOPE, (término municipal de Villarroya de los Pinares, comarca del Maestrazgo). (Hoja 543).}

Tras realizar la parada anterior, cabe continuar por la carretera autonómica aragonesa A 226. Así, ahora tras la bajada del puerto, se llegará a la población de Villarroya de los Pinares. Al llegar, convendrá tomar momentáneamente la carretera local de Aliaga, la TE - 8008. Al poco de tomarla, haremos una nueva parada junto al rio Guadalope (el cual va descendiendo junto a la carretera). Así, desde la parada anterior, habremos efectuado un recorrido cercano a los $11 \mathrm{Km}$. 
En este recorrido, hemos ido encontrando inicialmente, afloramientos de los materiales cretácicos que hemos visto en el puerto: Ios del Turoniense, del Cretácico Superior. Después, habremos ido descendiendo en la serie estratigráfica, encontrando niveles carbonatados del Cenomaniense, niveles de caolines del Albiense y finalmente niveles carbonatados del Aptiense, del Cretácico Inferior. Estos son los materiales que aparecen en el lugar de la parada.

En este lugar, al atravesar el rio Guadalope estos materiales, se ha originado un interesante estrecho, que constituye un LIG /Lugar de Interés Geológico) a nivel comarcal del Maestrazgo. FOTOGRAFIA 5.

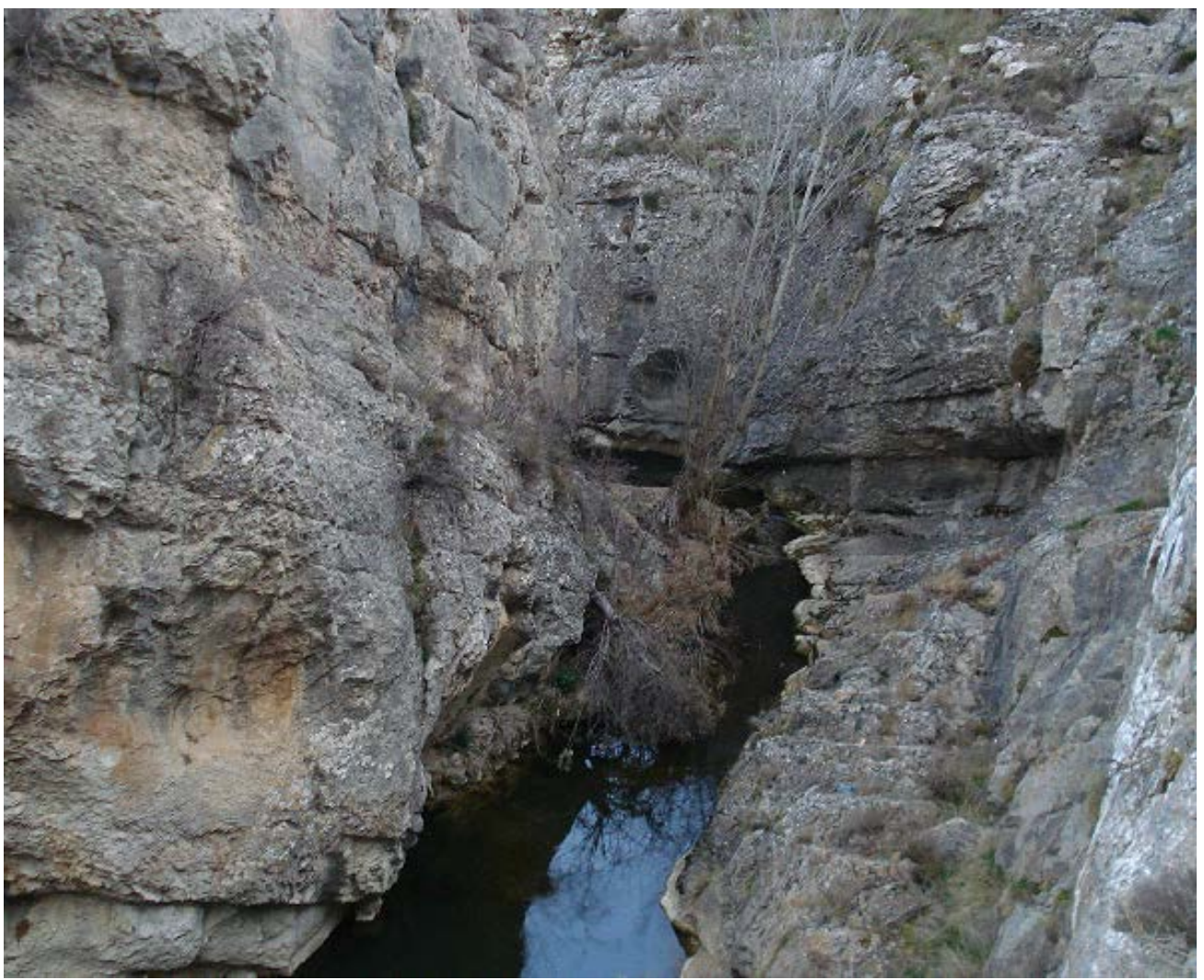

FOTOGRAFIA 5. PARADA 4

Un aspecto del río Guadalope y de sus estrechos en Villarroya de los Pinares

\subsection{PARADA 5 - CONDICIONAL. EL PUERTO DE SOLLAVIENTOS, CARRETERA A VALDELINARES, (término municipal de Allepúz, comarca del Maestrazgo). (Hoja 568).}

Tras realizar la parada anterior, cabe continuar por la carretera, yendo ahora hacía el poniente. Pronto se pasará por Villarroya de los Pinares, desde donde sale una carretera que se dirige hacía Aliaga, Nosotros continuaremos hacía Allepúz. Antes de llegar, pasaremos por el Puerto de Sollavientos, en donde haremos una nueva parada, a unos $13 \mathrm{Km}$ de la parada anterior. No 
obstante, al llegar al puerto, cabe tomar brevemente la carretera que va a Valdelinares (apenas unos 400 metros), para hacer la parada en ese lugar.

En este recorrido, hemos vuelto a circular por entre los afloramientos mesozoicos de la Cuenca del Maestrazgo, dentro del Sistema Ibérico, en donde estamos situados. Así, en esta zona predominan los arrumbamientos WNW-ESE (claramente ibéricos), aunque a menudo hay interferencias NNE-SSW y NE-SW (claramente catalanas). Desde este puerto, puede tenerse una amplia zona de visión de todas estas estructuras típicas de la Zona de Enlace entre el Sistema Ibérico y el Sistema Mediterráneo (o Catalánides).

Por otra parte, en este lugar (en las inmediaciones de la carretera a Valdelinares) hay unas mineralizaciones ferruginosas de carácter estratiforme. Se hallan asociadas a un "hard-ground" localizado entre las calizas cretácicas. Entre los minerales de hierro presentes cabe mencionar al HEMATITES y a la GOETHITA (terrosa y limonítica). Junto a ellos se encuentran también presentes la CALCITA y la DOLOMITA.

\subsection{PARADA 6 - CONDICIONAL. CRUCE DE CARRETERAS DE ALLEPUZ, (término municipal de Allepúz, comarca del Maestrazgo). (Hoja 568).}

Tras realizar la parada anterior, cabe continuar una vez más por la carretera, que se sigue encaminando hacía el poniente. Pronto se llegará a la población de Allepúz. Tras sobrepasarla, se llegará un cruce de carreteras, en donde efectuaremos una nueva parada. Así, desde el lugar anterior (Puerto de Sollavientos), habremos efectuado un recorrido 4’ $5 \mathrm{Km}$.

Como en el caso de la parada anterior, en este recorrido, hemos estado circulando por los afloramientos mesozoicos de la Cuenca del Maestrazgo, dentro del Sistema Ibérico, en donde estamos situados. Estos afloramientos pertenecen en su mayoría al Cretácico. También, es necesario hacer mencionar que en esta zona predominan los arrumbamientos WNW-ESE (claramente ibéricos), aunque a menudo hay interferencias NNE-SSW y NE-SW (claramente catalanas). Estamos, pues situados en la denominada Zona de Enlace entre el Sistema Ibérico y el Sistema Mediterráneo (o Catalánides).

Por otra parte, en este recorrido hemos pasado de la cuenca del río Guadalupe (tributario en Caspe del río Ebro) a la del río Alfambra (que en Teruel, al unirse al Guadalaviar) da origen al río Turia.

En este lugar hay un afloramiento de los niveles arenosos del Albiense, concretamente de la Formación Utrillas. Entre estos niveles hay bastante CAOLINITA, junto al CUARZO.

EN ESTE LUGAR FINALIZA EL RECORRIDO DE ESTE ITINERARIO

\section{BIBLIOGRAFIA}

CALVO, M. Et altri (1988).- Minerales de Aragón. Colección: temas geológicos, Edit. Mira, 210 pago. Zaragoza

GADMA. (2001).- Puntos de Interés Geológico de Aragón, Edit. Gobierno de Aragón, Departamento de Medio Ambiente (GADMA). 243 pago. Zaragoza 
MAESTRE, A. (1845).- Descripción geognóstica del Distrito Minero de Aragón y Cataluña. Anales de Minas, t. III, Madrid

MATA-PERELLÓ, J.M. (1991).- Inventario Mineralógico de la comarca de Gúdar - Javalambre. Rodeno, $n^{\circ} 34.26$ pago. Manresa

MATA-PERELLÓ, J.M. (1991).- Inventario Mineralógico de la Región del Turia (Sectores Orientales). Rodeno, $n^{\circ} 36.42$ pago. Manresa

MATA-PERELLÓ, J.M. (2003).- Recorrido geológico y mineralógico por las comarcas de la Comunidad de Teruel, de Gúdar-Javalambre y de la Tierra de Montalbán: desde Teruel y la Puebla de Valverde a Linares de Mora y a Utrillas. Inédito, 12 pago. Manresa

MATA-PERELLÓ, J.M. y MONTANÉ GARCÍA, P. (2004).- Recorregut de recerca geològica i mineralògica per les comarques de l'Alt Maestrat, del Maestrazgo i dels Ports: des de Vilafranca del Cid a Cantavieja, Mosqueruela; i de nou a Vilafranca, cap a Castellfort i Morella. Inédit, 12 págines. Manresa

MATA-PERELLÓ, J. M., POCOVÍ JUAN A. I VILALTELLA FARRÀS, J. (2006a).- Inventario de los indicios mineros, del patrimonio minero y geològico de la comarca del Maestrazgo. Inédito. 822 páginas. Manresa

MATA-PERELLÓ, J. M., POCOVÍ JUAN A. I VILALTELLA FARRÀS, J. (2006b).- Recorrido geológico y mineralógico por las comarcas del Maestrazgo y de las Cuencas Mineras: desde Cantavieja a Villarroya de los Pinares, Allepúz y a Galve. Inèdit. 14 páginas. Manresa

PEÑA MONGE, J.L. et altri (1984).- Geomorfología de la provincia de Teruel. Pub. Inst. Estudios Turolenses, 149 pago. Teruel 